\title{
THE COMPARATIVE EXTERNAL MORPHOLOGY AND REVISED TAXONOMY OF THE BRITISH SPECIES OF IDOTEA
}

\author{
By E. Naylor \\ Marine Biological Station, Port Erin
}

(Text-figs. I-II)

This paper aims at describing the external morphology of seven British species of Idotea from the functional and developmental aspects, thus revising earlier descriptions, such as those of Collinge (1917), which were based largely on adult specimens. Limitations of earlier descriptions are apparent, but some characters can be sifted from the older literature and combined with characters emphasized in this paper to give a schematic description of the seven species.

I am grateful to $\mathrm{Mr} \mathrm{J}$. S. Colman for criticism of this work, to Dr I. Gordon for facilities at the British Museum (Natural History), and for examining the Linnaean specimens of Oniscus marinus; and to Mr G. M. Spooner for help in the construction of the Key.

\section{Material ANd Methods}

The crustacean genus Idotea belongs to the suborder Valvifera of the order Isopoda, and the seven species of the genus which are dealt with in this investigation are I. linearis (Pennant), I. viridis (Slabber), ${ }^{1}$ I. baltica (Pallas), ${ }^{1}$ I. neglecta G. O. Sars, I. emarginata (Fabricius), I. granulosa Rathke, and I. pelagica Leach.

All these species, and no others, are recorded from the Isle of Man (Moore, I937, etc.), though the records of I. viridis are open to some doubt; the finding of $I$. viridis in this investigation seems to constitute the first certain record of the species in the Isle of Man (Naylor, I955a). Collinge (1917), in his review of the Idoteidae, records two other species from Britain: I. metallica Bosc. and I. sarsi Collinge. I. metallica does not seem to be a British resident, since only single specimens have been recorded, often from amongst Lepas on driftwood (Tattersall, I9II), whilst $I$. sarsi is synonymous with I. baltica. I have examined the type specimens of $I$. sarsi in the British Museum and they cannot be distinguished from I. baltica.

1 Holthuis (I949) maintains that $I$. viridis Slabber should now be called $I$. chelipes (Pallas), and that $I$. baltica (Pallas) should now be called I. marina (L.). Dr Gordon has examined the Linnaean specimens of 'Oniscus marinus', which resemble Idotea granulosa more than they do any other species. Neither of Holthuis's suggestions is adopted in the present paper. 
I have collected all seven species, the shore species I. granulosa and I. pelagica in particular, from various localities around the Isle of Man, and all but $I$. linearis were taken in some quantity. In addition, for morphological comparison with Manx specimens, material has been obtained from other localities in the British Isles.

Material was preserved in Baker's calcium formol solution, $5 \%$ sea-water formalin, or $70 \%$ alcohol. For microscopical examination appendages were mounted directly into glycerine from freshly killed specimens; semi-permanent preparations were made in Berlèse solution of glycerine jelly.

The staining and mounting methods given by Collinge $(1917,1918)$ proved impracticable. They are laborious and they entail the use of Canada balsam, the high refractive index of which makes accurate study of arthropod exoskeletons very difficult.

All measurements of body length were taken down the mid-dorsal line, irrespective of the shape of the telson. The larger specimens were measured against a non-parallax scale under a low-power dissecting microscope, and the smaller specimens were measured under a monocular microscope with a micrometer eyepiece.

The terminology adopted for the major divisions of the body is that used by Hansen (1925) and Howes (1939), namely:

Cephalon: the head and the first thoracic segment fused together.

Thorax: the last seven thoracic segments.

Abdomen: strictly speaking composed of six segments, but dorsally it appears to consist of three segments, the last of which is fused to the telson.

\section{GENERAL DESCRIPTION OF IDOTEA}

\section{Size and shape}

The length of a juvenile newly emerged from the brood-pouch varies from I to $3 \mathrm{~mm}$, according to the species. Males of the shortest species, I. pelagica, are recognizable at about $4 \mathrm{~mm}$, and they range to about $12 \mathrm{~mm}$. On the other hand, males of a larger species, I. emarginata, are identifiable at about $7 \mathrm{~mm}$ in some cases, and they range to about $30 \mathrm{~mm}$ in length. Within any one species, the size range of females is less than that of the males, and the female of a copulating pair is always smaller than its mate.

Shape varies from the long, filiform I. linearis, to the small, robust form of I. pelagica, and in all cases the ovigerous female is relatively broader than the male of the same species.

\section{Antennules (Fig. I) The Front Cephalic Appendages}

The antennules are the most anterior of the appendages. Each has a threejointed basal part and a flagellum consisting of one joint, the latter bearing on its antero-medial surface a number of aesthetascs. Each aesthetasc consists of 

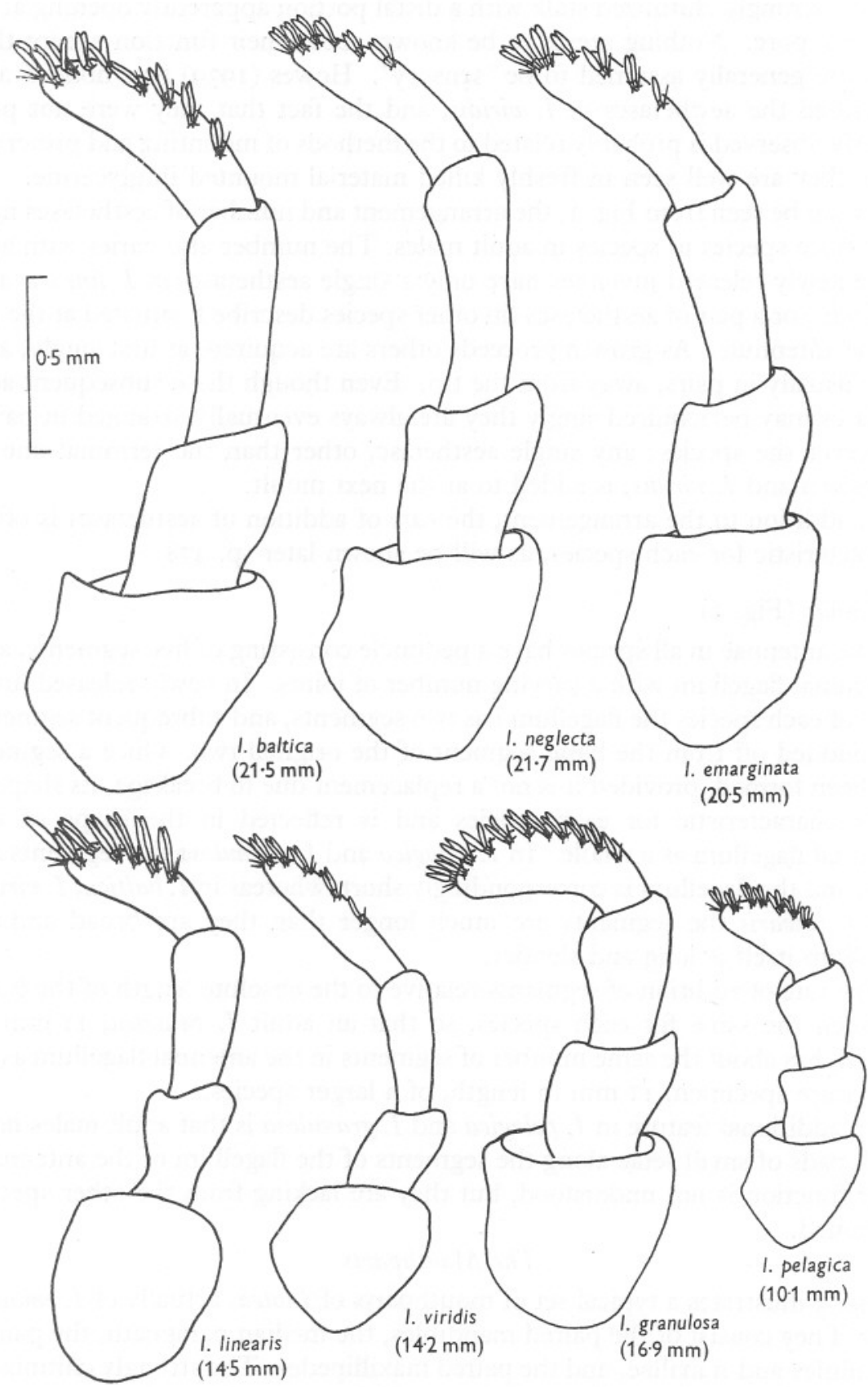

Fig. I. The right antennule of adult Idotea, seen from below. 
a fairly strongly chitinized stalk with a distal portion apparently opening at its tip by a pore. Nothing seems to be known about their function except that they are generally assumed to be 'sensory'. Howes (1939) first noticed and described the aesthetascs in $I$. viridis, and the fact that they were not previously observed is probably related to the methods of mounting and preservation; they are well seen in freshly killed material mounted in glycerine.

As can be seen from Fig. I, the arrangement and number of aesthetascs may vary from species to species in adult males. The number also varies with age, since newly released juveniles have only a single aesthetasc (in I. linearis and I. viridis) or a pair of aesthetascs (in other species described) situated at the tip of the antennule. As growth proceeds others are acquired, at first singly, and later usually in pairs, away from the tip. Even though these subsequent aesthetascs may be acquired singly they are always eventually arranged in pairs, whatever the species; any single aesthetasc, other than the terminal one of I. linearis and I. viridis, is added to at the next moult.

In addition to the arrangement, the rate of addition of aesthetascs is often characteristic for each species, as will be shown later (p. 478).

\section{Antennae (Fig. 2)}

The antennae in all species have a peduncle consisting of five segments, and a terminal flagellum with a varying number of joints. In newly released juveniles of each species the flagellum has two segments, and subsequent segments are budded off from the basal segment of the original two. Once a segment has been formed, provided it is not a replacement due to breakage, its shape is fairly characteristic for each species and is reflected in the shape of the antennal flagellum as a whole. In I. pelagica and I. granulosa the segments are stout and the flagellum is correspondingly short, whereas in I. baltica, I. viridis and I. linearis the segments are much longer than they are broad and the flagellum itself is long and slender.

The rate of addition of segments relative to the absolute length of the body is much the same for each species, so that an adult I. pelagica, II $\mathrm{mm}$ in length, has about the same number of segments in the antennal flagellum as an immature specimen, II $\mathrm{mm}$ in length, of a larger species.

An additional feature in I. pelagica and I. granulosa is that adult males have thick pads of small setae along the segments of the flagellum of the antennae; their function is not understood, but they are lacking from the other species examined.

\section{The Mouthparts}

Fig. 3 illustrates a typical set of mouthparts of Idotea, actually of I. emarginata. They consist of the paired mandibles, the median paragnath, the paired maxillules and maxillae, and the paired maxillipedes. The strongly chitinized, plate-like labrum fits in front of the mandibles and projects downwards and backwards; it is not figured. 


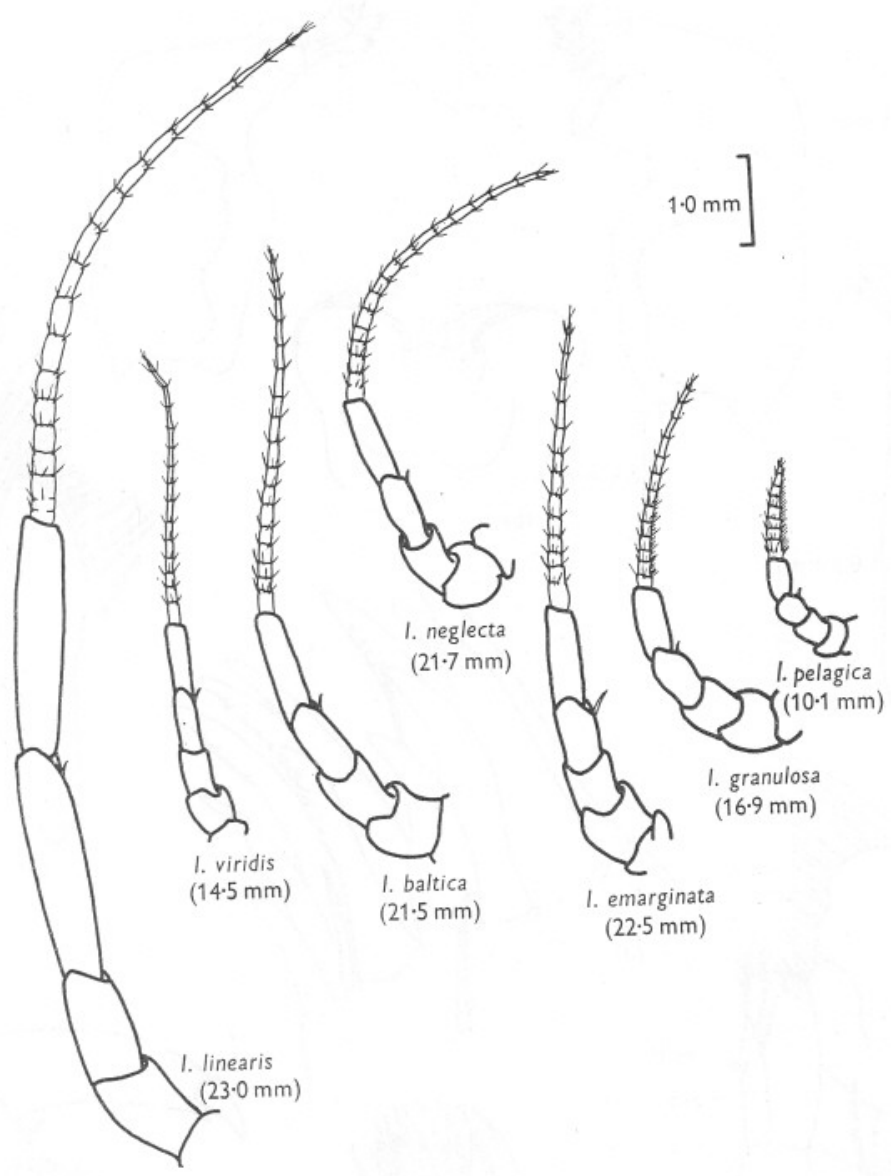

Fig. 2. The right antenna of adult Idotea, seen from above.

\section{Mandibles (Fig. 3a)}

It has not previously been noted that the mandibles of Idotea are asymmetri$\mathrm{cal}$, though the feature is probably common in the Malacostraca as a whole (Calman, I909). Each mandible is L-shaped; one arm has strong muscular attachments and lies horizontally, parallel to the sides of the head, whilst the other arm points downwards and inwards, meeting its fellow medially on the ventral side of the head. Ventrally placed on each mandible is a strongly chitinized incisor process, and above this is the lacinia mobilis, which is more strongly chitinized on the left mandible than on the right. When the mandibles are closely apposed, the incisor process of the right appendage fits between the lacinia and the incisor process of the left side. 


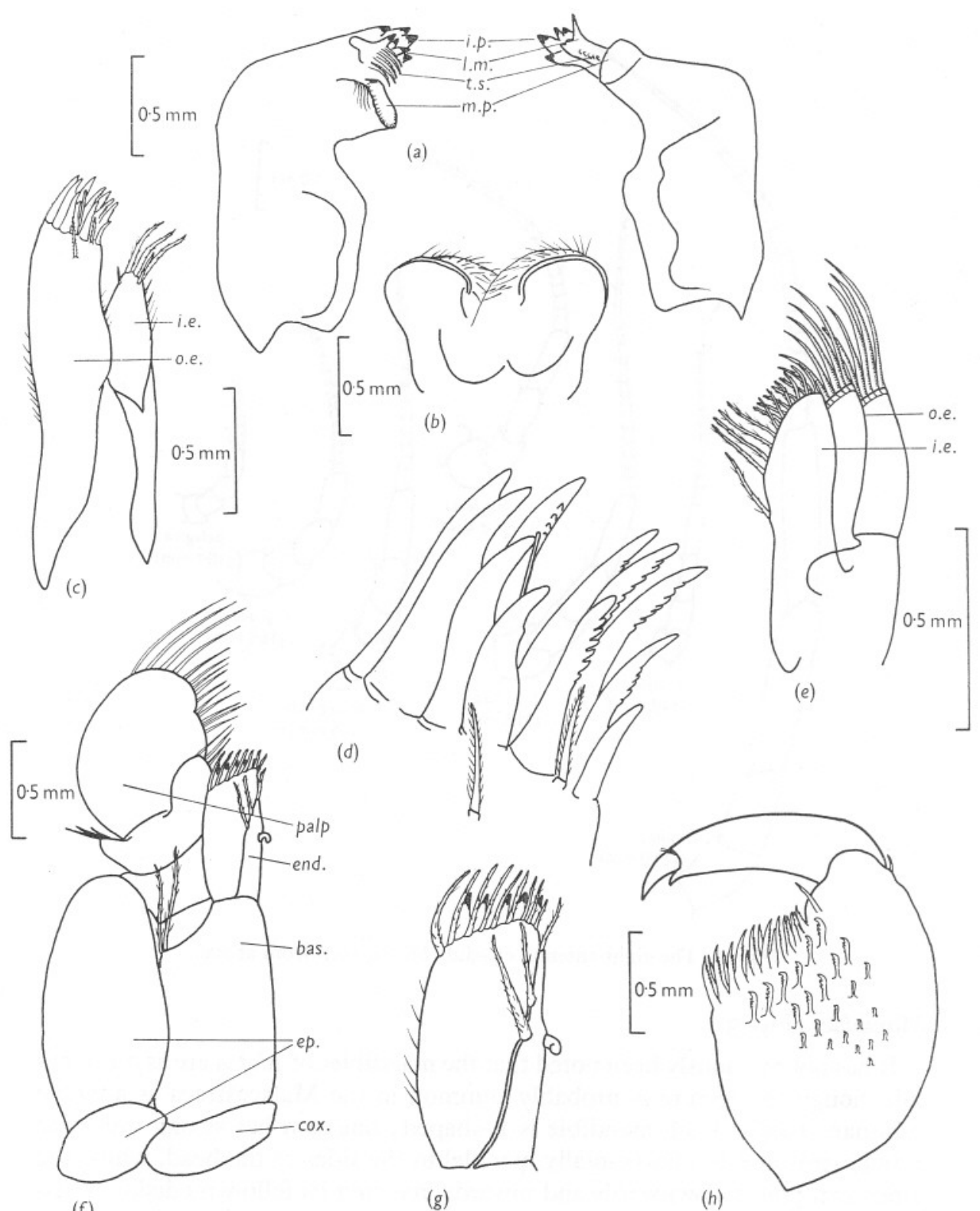

(f)

(g)

Fig. 3. The mouthparts of an adult $I$. emarginata, $20.5 \mathrm{~mm}$ in length: (a) mandibles, from above (i.p., incisor process; l.m., lacinia mobilis; t.s., toothed spines; m.p., molar process); (b) paragnath; (c) right maxillule, from below (i.e., inner endite; o.e., outer endite); (d) tip of outer endite of maxillule; (e) right maxilla, from above (o.e., outer endite; i.e., inner endite); $(f)$ left maxillipede, from above (end., endite; bas., basipodite; ep., epipodites; cox., coxopodite); $(g)$ endopodite of maxillipede; $(h)$ terminal joint of $I$ st leg. 
Above the lacinia is a row of upwardly curving toothed spines, and above the spines is the molar process. The molar processes of the two mandibles are arranged differently; the left molar process faces upwards, whilst that of the right side faces downwards.

The mandibles lack any trace of a palp.

\section{Paragnath (Fig. 3b)}

The ventral mouth opening, bordered anteriorly by the labrum and laterally by the mandibles, is bordered posteriorly by the median, bilobed paragnath. Between the left and right lobes of the paragnath is a median groove into which project brush setae of the other appendages (see below). The median surfaces of the paragnath are covered with curved spines, which project forwards and upwards into the oral cavity.

\section{Maxillules (Fig. 3c)}

Each maxillule has two endites, the large outer endite and the smaller inner endite, each having fairly strong muscular attachments. The outer endite has at its tip twelve chitinized spines and two flexible flattened setae fringed with small stiff bristles (Fig. $3 d$ ). This arrangement of spines and blades is the same for each species, throughout the whole of the life cycle.

The maxillules, like the maxillae and the maxillipedes, are attached posteriorly and project forwards below the paragnath. The ventral spines of the outer endite, which are used in scraping the food material, appear spatulate and are mostly without teeth; one of this group is a rod-like structure. The upper (inner) spines, except for the small median one, are usually strongly toothed; these spines serve to push food into the mouth (Naylor, I955 b).

The inner endite again has a constant number of processes at its tip. They consist of four brush setae (three long and one short), with a small spine at the bases of the setae.

\section{Maxillae (Fig. 3e)}

These are more fragile, flattened structures, much less chitinized than the maxillules. Each again has two endites, the outer endite itself being bilobed. Both lobes of the outer endite have a row of combing setae along their anterior edges and, as can be seen in Fig. $3 e$, the outer setae show an increase in size.

The inner endite lies above and medial to the outer endite. It has two rows (upper and lower) of small brush setae, merging to smoother spines laterally, and there are, placed medially, two to four large brush setae analogous to those on the inner lobe of the maxillule.

\section{Maxillipedes (Fig. $3 f$ )}

The maxillipedes are broad, flattened appendages covering the other mouthparts ventrally. Arising laterally from the coxa are two epipodites, and arising 
medially is the basis. Articulating in front of the basis are the medial endopodite and the distal four-jointed palp, the outer lobe of which bears long smooth spines.

The endopodite (Fig. $3 g$ ) is turned vertically upwards along its medial edge and is thus L-shaped in cross-section. The appendage of each side has a single coupling hook situated on the vertical flange, and these interlock to make the maxillipedes, functionally, a single structure. The L-shape of the endopodite was first described by Howes (1939) for I. viridis, but it is common to all the seven species.

Along the upper edge of the endopodite, and extending forwards and laterally across the anterior border, is a row of brush setae, again comparable with those of the preceding two pairs of appendages. Beneath the brush setae is a row of heavily chitinized, smooth, scraping spines which have a curious double chisel edge at their tip (Naylor, I955 b).

A feature not mentioned by Collinge (I9I7) is to be found on the maxillipede of the adult female. The appendage as described so far is typical of all specimens, but in females with a brood pouch there is, in addition, on the inner posterior border of the maxillipede, a small lappet fringed with setae (Fig. 4e). This projects into the brood pouch, since the first oostegite covers the base of the maxillipede, and it appears that movements of the maxillipede cause the lappet to create a current of water over the developing eggs in the brood pouch. Ovigerous females, otherwise at rest on weed, and certainly not feeding, are often seen to raise and lower their maxillipedes with some regularity.

Calman (1909), not specifically referring to Idotea, states that 'in ovigerous females of...certain genera of the Valvifera the coxopodite bears a small lappet, fringed with setae, projecting backwards into the marsupium'. By virtue of the position of this structure, and its occurrence in the adult female, Calman suggests that the lappet may be homologous with the oostegites of the first five thoracic segments.

\section{Legs The Appendages of the Thorax}

The thorax is composed of seven segments, and in adult specimens each segment bears a pair of walking legs. Newly released young have only six pairs of legs, the last segment being small and devoid of appendages. After two moults, in I. emarginata and probably in other species as well, the seventh segment acquires the first signs of a pair of legs in the form of a pair of small rudiments projecting forwards. Only after a third moult does the animal acquire its full complement of legs.

The first pair of limbs are short and each has a palmate distal joint (dactylopodite), which bears rows of comb spines on its inner surface (Fig. $3 h$ ). This surface is held beneath the mouthparts during feeding, and it aids in keeping them free of debris. 
On the more posterior segments the legs become longer and more slender, being particularly so on the last three thoracic segments. None of the last six pairs of legs are used in feeding, but some are modified in the adult male and

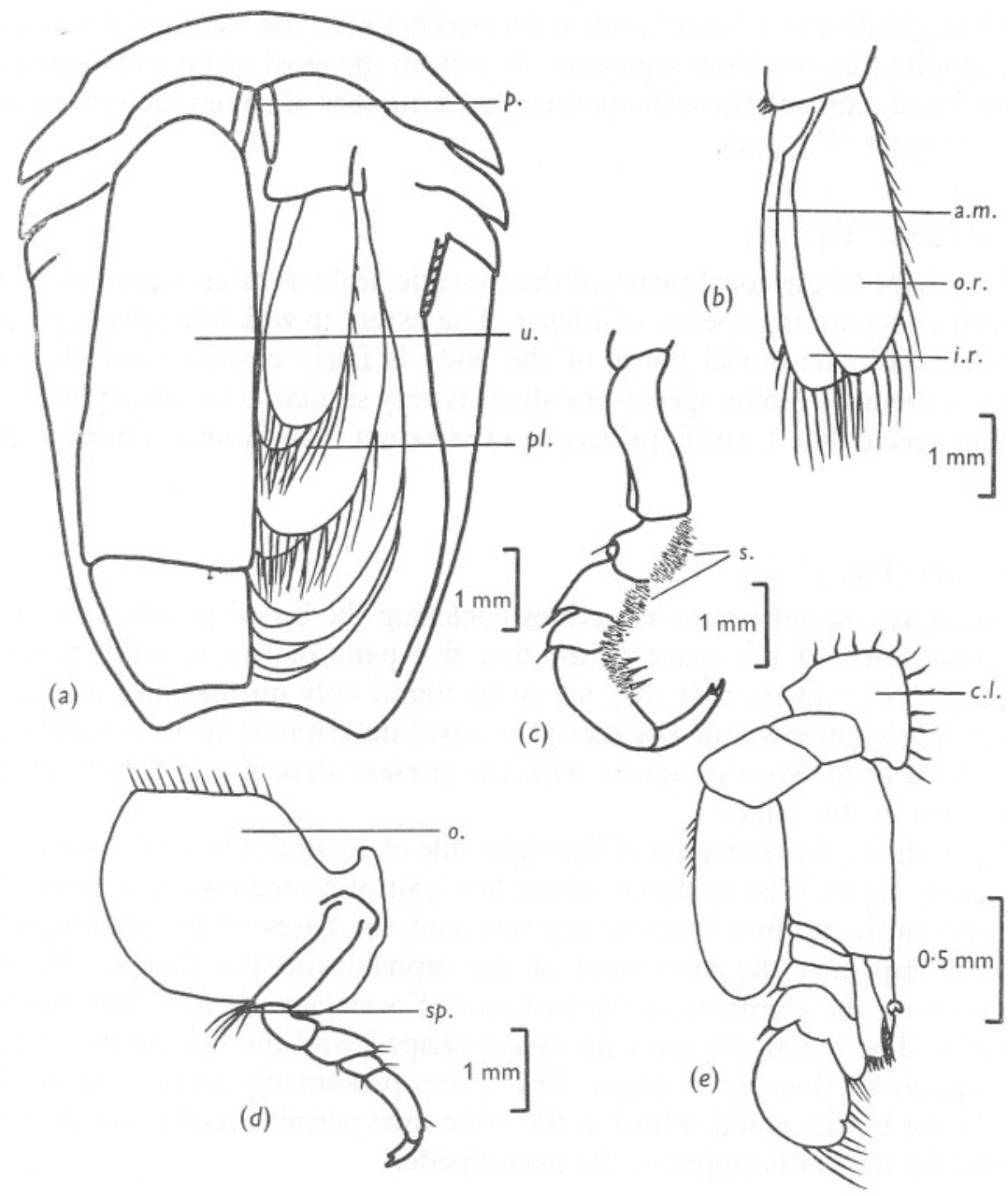

Fig. 4. Secondary sexual characters of Idotea emarginata: (a) abdomen of male, from below, showing penes (p.) (u., uropod; pl., pleopod); (b) appendix masculinus (a.m.) on the second pleopod of the male (o.r., outer ramus of pleopod; i.r., inner ramus); (c) 2nd leg of adult male, showing pads of finesetae (s.); (d) 4th leg of adult female, with spines (sp.) and oostegite (o.); (e) maxillipede of adult female, showing lappet (c.l.).

female. The second pair of legs of males of all species (and all succeeding legs in I. linearis and I. pelagica) bear thick pads of fine setae on their inner surfaces (Fig. 4c). This pair of legs is used by the male in clasping the female in the 
periods of pairing prior to copulation, when it would appear that the pads of setae give a good grip on the smooth surface of the female.

In adult females the first five or six legs acquire spines which support the oostegites in their task of forming a brood pouch. The legs flex inwards beneath the body and a 'knee' joint is formed between the ischiopodite and the meropodite, the two basal segments. It is from the most distal and inner edge of the basal segment, the ischiopodite, that a number of spines fan out beneath the oostegites (Fig. 4d).

\section{Coxal Plates (Fig. II)}

The shape of the coxal plates of the thoracic limbs is often regarded as important in separating species of Idotea. The extent to which the plates project from beneath the dorsal plates of the body is fairly characteristic for each species, though in some species the shape is very similar. The coxal plates of a slender species like $I$. viridis project to a less extent than those of a more robust species.

\section{Oostegites (Fig. 5)}

Oostegites, membranous structures enclosing the brood pouch, arise from the inner parts of the coxae of the first five pairs of legs of adult females. Collinge (I9I7) states that they are to be found only on the third and three succeeding segments, but Kjennerud's (1950) description of the oostegites of I. neglecta from Norway agrees with the present description for all species dealt with in this paper.

Fig. 5 shows the oostegites of the right side of an adult female $I$. emarginata seen from above. The members of the first pair of oostegites are so shaped as to cover both the first thoracic segment and the bases of the maxillipedes, without impeding the movement of the cephalon on the thorax. Hooked processes on the members of the first pair of oostegites serve to link the two together. The remaining ones are saucer-shaped, and the last two pairs bear long spines on their inner edges. The spines presumably serve to retain the eggs in the brood pouch, whilst at the same time permitting the flow of water created by the coxal lappet of the maxillipede.

\section{The External Genitalia}

The male genital ducts open at the tips of the paired penes, the latter arising from the first abdominal segment and projecting back towards the bases of the pleopods (Fig. 4a).

The female genital ducts open on the fifth thoracic segment. 


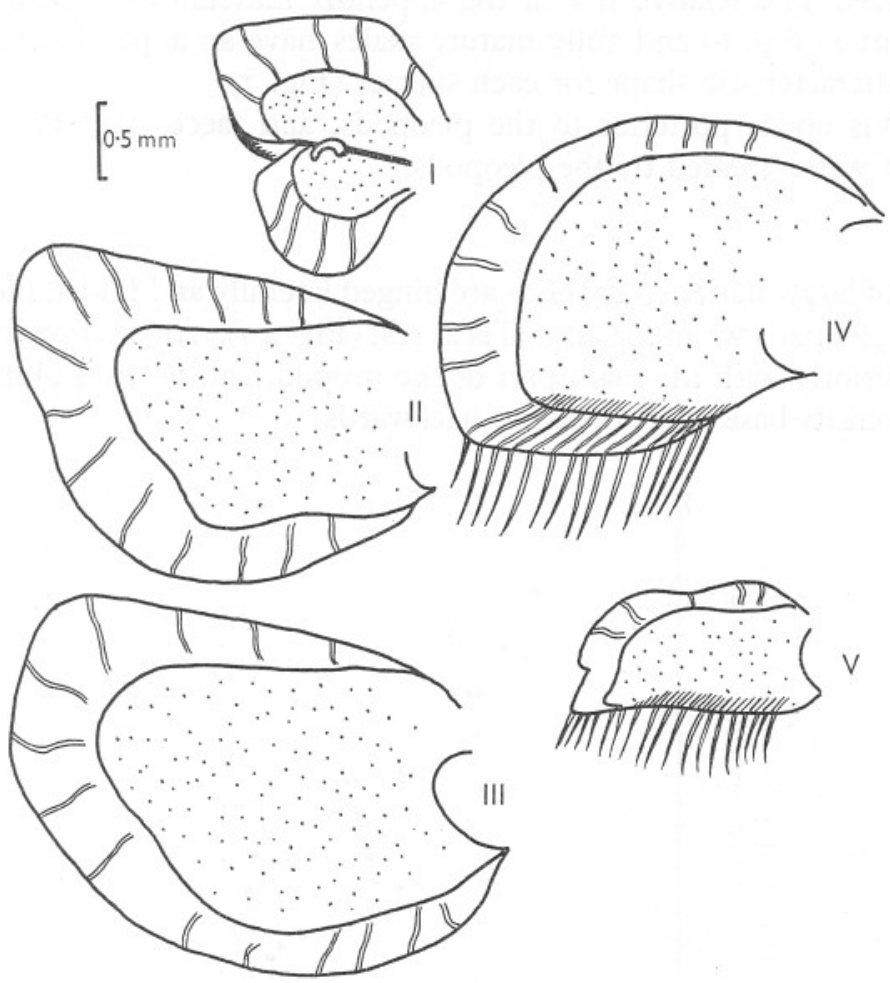

Fig. 5. The right oostegites of an adult female I. emarginata, from legs I-V, seen from above.

\section{The Appendages of the Abdomen}

Idotea illustrates the typical malacostracan arrangement of six pairs of abdominal limbs, namely, five pairs of pleopods and one pair of uropods. Fusion of the segments themselves, however, is such that only three are distinguishable, the last of these being incompletely fused with the telson.

\section{Pleopods}

The pleopods consist of five pairs of bilobed, lamellar structures, arising close together behind the last thoracic segment and projecting backwards beneath the abdomen (Fig. 4a). The current of water created by movement of these appendages serves for both respiration and swimming.

The first two pairs of pleopods possess long setae fringed with fine hairs, but such setae are lacking from the other pleopods. The inner ramus of the second pleopod of adult males bears a stylet, or appendix masculinus (Fig. $4 b$ ), a paired structure which serves to transfer sperm from the penes to 
the oviducts. The relative size of the appendix masculinus decreases as the male matures (Fig. 6) and fully mature males have an appendix masculinus of fairly characteristic shape for each species (Fig. 7).

The anus opens posterior to the pleopods, and faeces are shed into the current of water created by the pleopods.

\section{Uropods}

A pair of large, flattened uropods are hinged laterally and folded medially to cover the pleopods when the animal is at rest (Fig. 4a). An endopodite articulates posteriorly with the main part of the uropod, and it has a plumose seta arising from its base and projecting backwards.

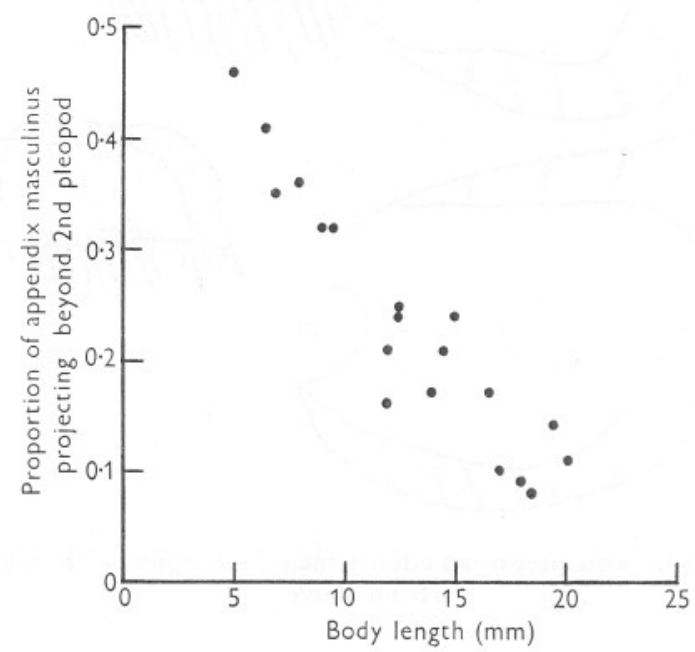

Fig. 6. The proportion of the appendix masculinus which projects beyond the second pleopod, plotted against the body length in $\mathrm{mm}$, for I. granulosa.

\section{The Telson}

All species begin life with a similar, uniformly rounded telson, but as growth proceeds each species acquires a characteristic telson shape. Fig. 8 illustrates the shape of the telson of specimens of various sizes of all species studied; it shows the close similarity of telson shape in young forms, even of such species as I. baltica and I. emarginata.

\section{The Taxonomic Value of Various Structures}

\section{Numbers of Aesthetascs and Antennal Segments}

Howes (1939) noted that the number of aesthetascs and antennal segments in I. viridis increased as the animal increased in length. With sufficient data he was able to divide the growth of $I$. viridis into a series of clear-cut growth 
stages (instars), each growth stage having a characteristic number of antennal segments and aesthetascs, and having a characteristic size-range. The characters of one stage changed to those of the succeeding one after a moult.
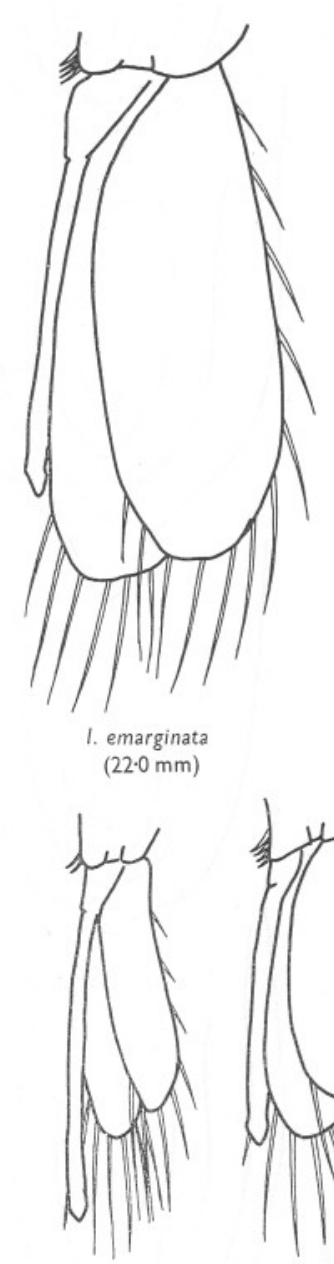

1. linearis (17.8 mm)

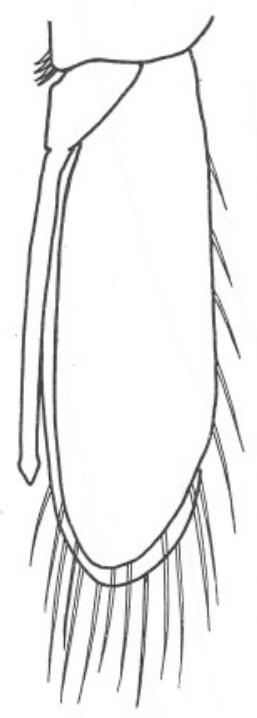

1. neglecta

(21.1 mm)

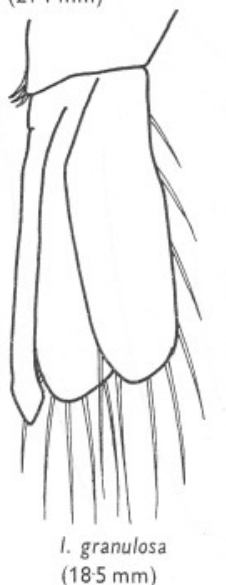

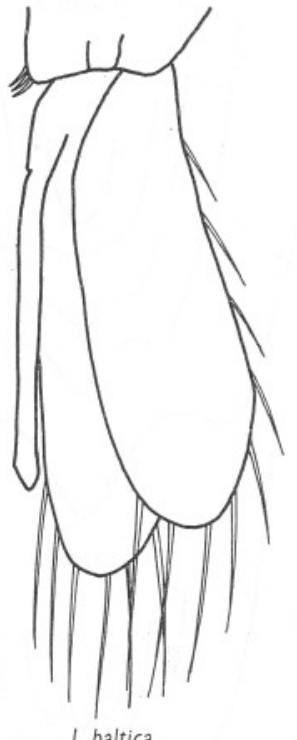

$(23.4 \mathrm{~mm})$

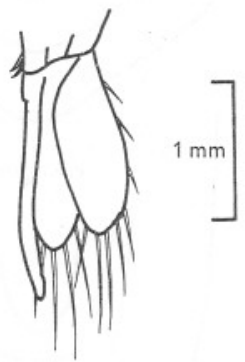

1. pelagica

(10-2 mm)

Fig. 7. The second pleopod of male Idotea, showing the appendix masculinus in each case.

Kjennerud (1950) treated I. neglecta in the same way and obtained a similar series of instars. Obvious differences between similar stages of the two species led Kjennerud (p. I5) to express the view that 'very little is known of the first stages of development in Idotea spp., although it is possible that the relation between the size of the animal, the joints on the flagellum of the antenna 


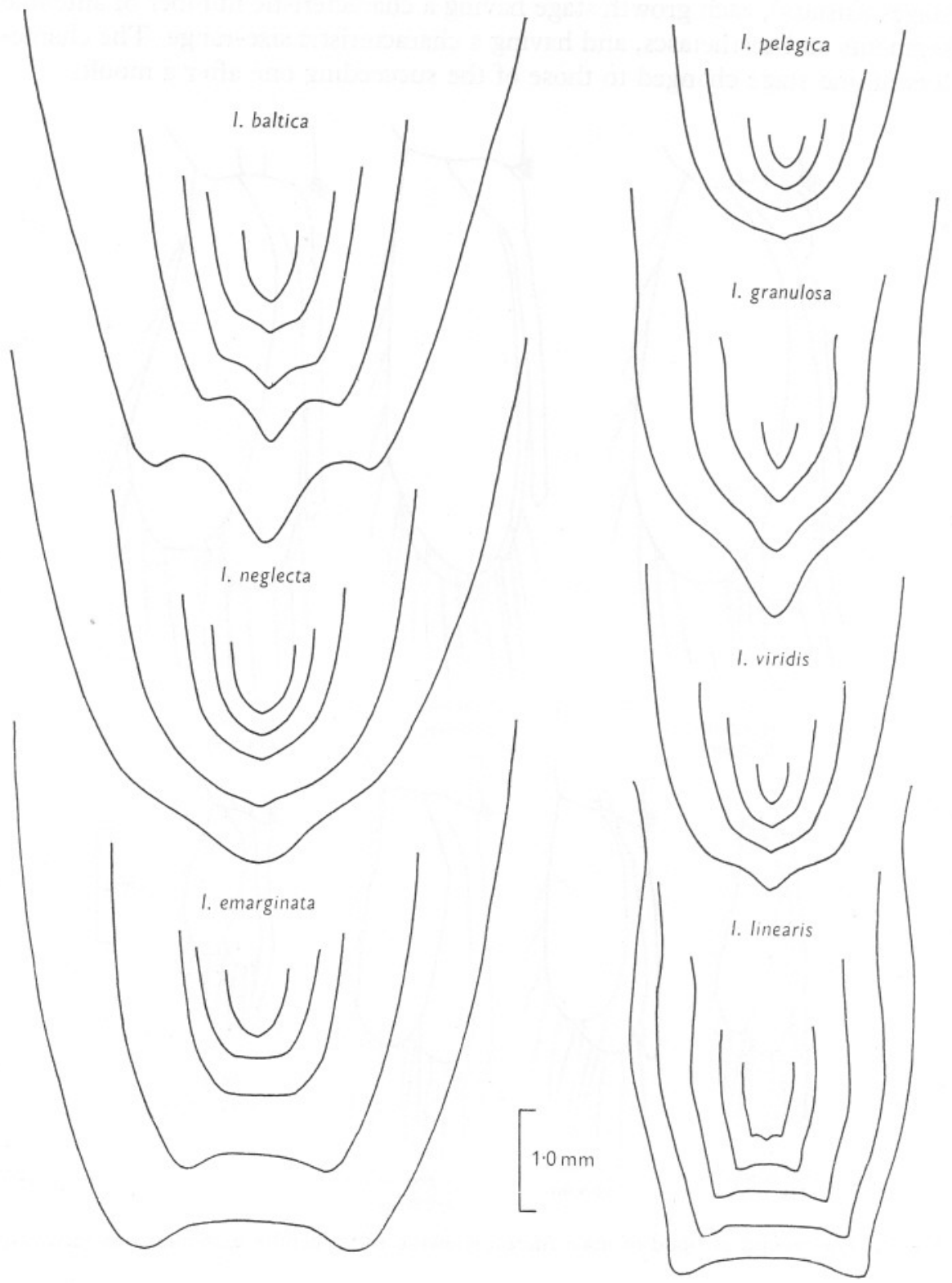

Fig. 8. The development of the telson of seven species of Idotea. The body lengths of the specimens under each species were as follows: I. baltica $(2 \cdot 2,5 \cdot 4,8 \cdot 5,12 \cdot 0$ and $20 \cdot 0 \mathrm{~mm})$; I. neglecta $(2 \cdot 7,4 \cdot 3,6 \cdot 6,13 \cdot 8$, and $19 \cdot 0 \mathrm{~mm}) ;$ I. emarginata $(2 \cdot 2,4 \cdot 6,6 \cdot 8,12 \cdot 8$ and $19 \cdot 5 \mathrm{~mm})$; I. pelagica $(\mathrm{I} \cdot 7,3.7,7.2$ and $10.2 \mathrm{~mm}) ;$ I. granulosa $(\mathrm{I} \cdot 9,6.3,10.8$, and $16.2 \mathrm{~mm})$; I. viridis $(\mathrm{I} \cdot 7,4 \cdot 6,8 \cdot 0$ and $\mathrm{I} 4 \cdot 0 \mathrm{~mm})$; I. linearis $(3 \cdot 5,6 \cdot 3, \mathrm{II} \cdot 0$, $\mathrm{I} 6 \cdot 2$ and $22 \cdot 9 \mathrm{~mm})$. 
and the number of sense rods on the distal joint of the antennula will prove to be so characteristic for each species that one can distinguish not only between various Idotea species, but also between the different instars within each species'.

The principle has been applied to Manx specimens of I. emarginata, but it was found difficult to divide the growth of this species into discrete instars (Naylor, I955c). Greater variation than was found by Kjennerud, both in the number of aesthetascs and in the number of joints in the antennal flagellum,

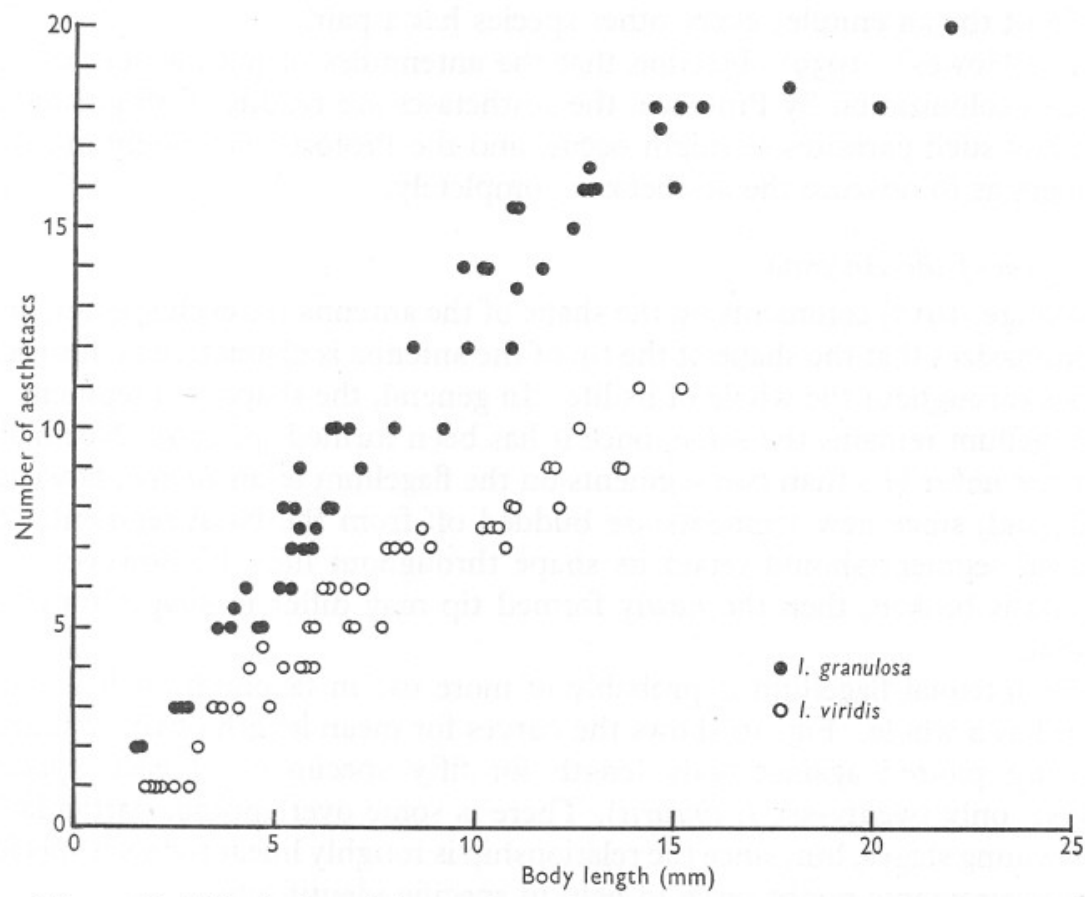

Fig. 9. Individual plots of the number of aesthetascs against body length, for fifty specimens each of $I$. viridis and $I$. granulosa.

limits the general application of the method; this applies not only to I. emarginata but to Manx and other British specimens of I. neglecta, I. viridis, and other species as well. In addition, as has been stated earlier (p. 470), the rate of addition of antennal segments with increasing body length is much the same for each species, except $I$. viridis.

Even, however, if division into instars and its use in taxonomy is subject to limitation, there is some taxonomic value in plotting the number of aesthetascs against the length of the body of the idoteid, irrespective of instars; the two species $I$. viridis and $I$. granulosa, which are often confused, may be completely separated by this character. Fig. 9 shows individual plottings of the number of aesthetascs against body length, for specimens of $I$. viridis and I. granulosa. 
It will be seen that the two species hardly overlap, and they may be separated at all sizes; except in large specimens I. granulosa has more aesthetascs than its body length expressed in millimetres, whilst $I$. viridis generally has fewer.

\section{The Form of the Antennule}

The arrangement of the aesthetascs, rather than their number, is probably of more value in taxonomy. Reference to Fig. I shows that $I$. viridis and I. linearis may be separated from all other species by their single aesthetasc at the tip of the antennule; every other species has a pair.

As to Howes's (1939) objection that the antennules of marine species are liable to colonization by Protozoa, the aesthetascs are readily distinguishable from any such parasites as might occur, and the Protozoa are rarely in such numbers as to obscure the aesthetascs completely.

\section{The Form of the Antenna}

Collinge (I9I7) comments on the shape of the antenna for each species, and he emphasizes that the shape of the tip of the antenna is characteristic for each species throughout the whole of its life. In general, the shape of a segment of the flagellum remains the same, once it has been formed (p. 470). Normally there are never less than two segments on the flagellum of an Idotea, however small, and, since new segments are budded off from the basal segment, the terminal segment should retain its shape throughout life. If, however, the antenna is broken, then the newly formed tip may differ in shape from the original.

The antennal flagellum is probably of more use in taxonomy if it is considered as a whole. Fig. Io shows the curves for mean length of the antennal flagellum plotted against body length for fifty specimens of each species studied (only twenty-six $I$. linearis). There is some overlapping, particularly in the young stages, but, since the relationship is roughly linear for each species the measurements might serve to help in specific identification.

The variation in the shape of the antennal flagellum, from species to species, is best understood when the mode of life of each species is taken into consideration. Species living in situations exposed to wave action have short, stout appendages, whilst those living in sheltered situations have more fragile appendages (Naylor, I955 $a$ ).

\section{The Maxillule}

Collinge (I9I7) figures and describes the tip of the outer endite of the maxillule for each species, and he states that there is a characteristic number of maxillulary spines for each species. Using these data in a key, Nierstrasz \& Steckhoven (I930) separate five species of Idotea on the number and degree of toothedness of the spines on the maxillule. More recently, Howes's (1939) description of the spines in I. viridis and Kjennerud's (1950) description of those for 
I. neglecta both differ from the data given by Collinge for the same species.

The present descriptions again differ, in that every species has the same number of spines on the maxillule, namely, twelve (p. 473). This has been verified in specimens of all species from many British localities, and Kjennerud's description for $I$. neglecta from Norway agrees with British specimens except that it does not include the two blade-like structures fringed with setae (Fig. $3 d$ ). Howes's description for 1 . viridis omits the most slender of the spines, as well as the blade-like structures.

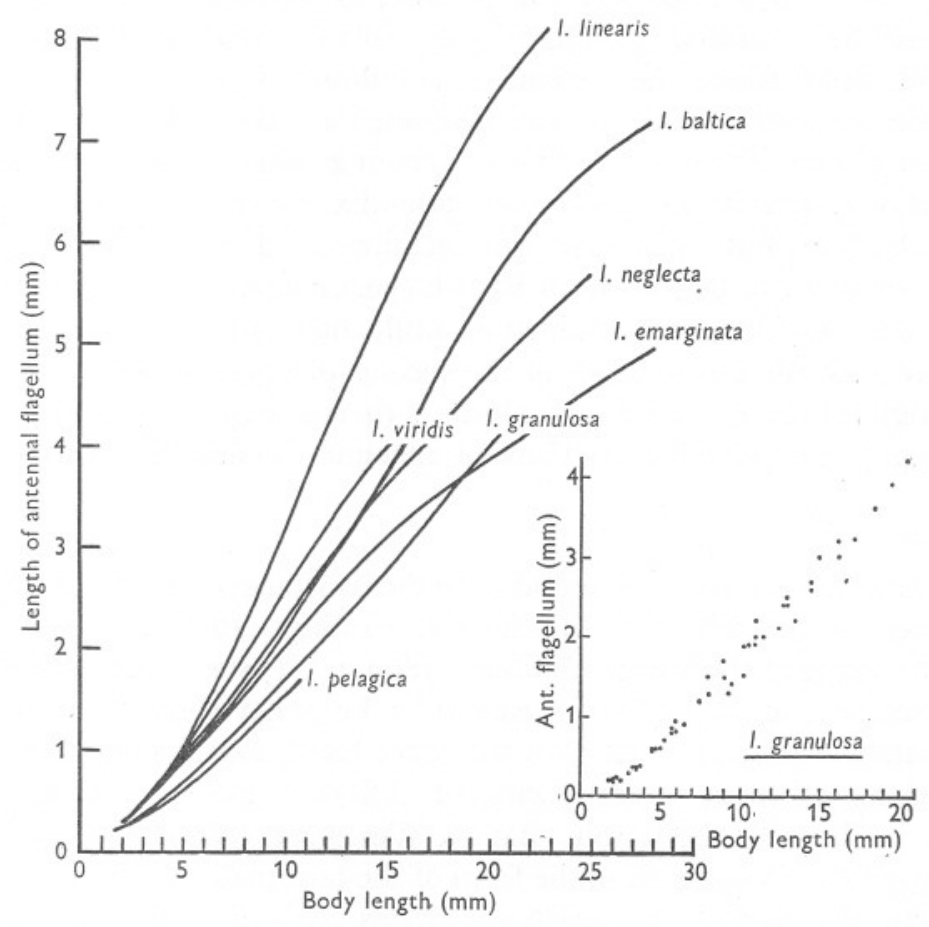

Fig. Io. Mean curves, showing the length of antennal flagellum plotted against body length, for seven species of Idotea. Inset shows individual plots for fifty specimens of I. granulosa.

The degree of toothedness of the spines varies from species to species, and sometimes throughout the life of each species. Broadly speaking though, the ventral spines, used in scraping, are less toothed than the dorsal ones, which are used in pushing food masses upwards between the mandibles (Naylor, $1955 b$ ).

In conclusion, it can be said that observations on the maxillules of Manx and other British specimens of Idotea do not conform with descriptions given by Collinge (I9I7), and the key for identification of Idotea given by Nierstrasz \& Steckhoven (I930) appears to be partly invalidated. 


\section{The Coxal Plates}

A taxonomic feature often emphasized, and particularly so by Dollfus (1894-5), was the shape of the coxal plates. There is some variation in the form of the plates as growth proceeds, as has been described for I. viridis by Howes (1939), but the feature still seems to be of some importance in separating the species (p. 476).

\section{The Appendix Masculinus of the Second Pleopod}

Though Sars (1899) regarded this structure as important, and figured it for each species he described, Collinge (I917) fails to mention it in his review. Kjennerud (1950) found the appendix masculinus of I. neglecta to be much longer, relative to the length of the pleopod, than allowed for by Sars, and Kjennerud quotes Tattersall (I906) as agreeing with this objection. Manx specimens of $I$. neglecta again show an appendix masculinus longer than that described by Sars, but still further modifications of all Sars's descriptions are necessary since it can be shown, in British specimens of all species, that once the appendix masculinus has attained its adult shape it increases in length at a slower rate than the inner ramus of the second pleopod (p. 478).

The length of the appendix masculinus is therefore of use in separating the species (Fig. 7), provided the length of the specimen is taken into consideration.

\section{The Telson}

Conflicting reports are to be found as to the constancy of shape of the telson of each species, throughout its life-history. Collinge (I9I7) found few variations in the shape of the telson, and Sars (I899, p. 8I) states that he found the terminal segment of the body of $I$. baltica 'to be pretty constant even in very young forms'. Tattersall (I906), on the other hand, found some difficulty in distinguishing between young forms of different species because of the similarity in shape of the telson. Bate \& Westwood (I868, p. 38I) describe for I. tricuspidata, 'variations in the form of the terminal segment of the body, with length and size of respective specimens', but it should be noted, as Kjennerud points out, that the telson shapes illustrated for I. tricuspidata by Bate \& Westwood probably belong to three or four different species.

Howes (1939) discussed these points of view in the light of his own work on $I$. viridis, in which changes in shape of the telson did take place as the animal aged, and he found (p. 307) 'reason to believe that changes in shape of the abdomen occur during the growth of $I$. baltica as they do in I. viridis'.

The present investigation reveals the fact that changes take place in the shape of the telson of all species, each beginning life with a more or less uniformly rounded telson and only acquiring the typical adult shape later in life (Fig. 8). Thus, as with many features, though the adult telson shape is charac- 
teristic for each species, the juvenile telson shapes are by no means distinct from one another. Sars's figures of adult telsons are very good for the species which he deals with, but the figures given by Collinge are sometimes inadequate.

\section{An additional factor: Habitat}

The ecology of Idotea is discussed elsewhere (Naylor, I955a), and it is shown that each species has a fairly characteristic habitat. I. pelagica and I. granulosa are resident intertidal species, $I$. viridis is a brackish water form, and $I$. emarginata, I. neglecta, $I$. baltica and $I$. linearis are chiefly sublittoral. If therefore the habitat of a specimen is known it could well aid in identifying that specimen.

\section{Discussion}

Any attempt to classify organisms must seek differences which are readily measured, and which are constant for similar stages of the organisms concerned. Thus, in the case of Idotea, which attains adult form only gradually, rather than by a distinct metamorphosis, any differences must ideally persist over the whole development of the animal. This factor appears to limit many of the earlier descriptions; the full extent of the life-cycle seems not to have been covered in the descriptions such as those by Collinge (I9I7), and some cases of apparent misidentification are to be found in subsequent literature.

It is with this in mind that Howes (1939, p. 307) ends his discussion of the growth of $I$. viridis with the statement that 'only the breadth/length ratio of the cephalon and the number of spines on the outer lobe of the maxillule emerge as constant throughout the whole period (of growth)'. With regard to these characters, it has been shown above (pp. 473 and 483 ) that the number of spines on the maxillule is useless as a taxonomic character because all species have the same number; and reference to the species-by-species descriptions given below will show the close similarity of the cephalon measurements. Therefore, of the characters studied by Howes, none would appear to be of certain value in taxonomy.

The general study of growth of all species does, however, reveal some differences of value in separating species. What is more, in the light of Huxley's (I932) emphasis of the importance of allometry in taxonomy, rates of change, such as the rate of addition of aesthetascs on the antennule, might well be used in separating some species.

The problem, therefore, in giving adequate taxonomic descriptions of species, is to fit the recent principles of experimental taxonomy with their element of 'change', into the older concept of the more 'static' nature of the species (see Gilmour, I952). This applies even more if local differences are found within an individual species; $I$. viridis, for example, may mature at different instars in different localities (Howes, 1939), and this may well be 
true of other species as well. More work is clearly needed to determine any geographical variation within any one species.

An attempt has been made to embody the characters of later developmental stages, as well as those of adults, in the following key.

\section{KeY to BRITISH IDOTEA}

(The smallest specimens, up to about $6 \mathrm{~mm}$, are disregarded.)

I. Telson with apical border straight or concave.

(a) Body elongate, narrow: mesosome segments 2-7 less than twice as wide as long. Antenna $>\frac{1}{2}$ body length. Coxal plates very small, not reaching posterior border of any segment (Fig. II). Telson with lateral corners acutely angled, and with a smaller median spine in youngest specimens. Colour brown-green, with white or darker markings. Mainly sublittoral, in fully marine conditions.

\section{I. linearis (L.)}

(b) Body less elongate: mesosome segments 2-7 twice as wide as long, or more. Antenna $<\frac{1}{2}$ body length. Coxal plates $3-7$, at least, reaching posterior border of segment.

(i) Telson with apical border concave and angulate at sides (adult) or straight with rounded corners (juvenile), the sides somewhat rounded (Fig. 8). Coxal plates 5 and 6 not sharply angled (i.e. angle $>45^{\circ}$ ). In shallow coastal waters; mainly sublittoral.

I. emarginata $(\mathrm{Fab}$.

(ii) Telson with apical border straight, with rounded corners (adult) or widely rounded corners (juvenile); the sides straight. Coxal plates 5-7 very sharply produced, making angles of less than $45^{\circ}$. An infrequent, offshore species.

I. metallica Bosc.

2. Telson with apical border produced and more or less angulate in centre.

(a) Telson apical border tridentate or nearly so; median process acute and well protruding. Green or brown, often with pattern of spots and lines. Marine, chiefly sublittoral, in shallow water.

I. baltica (Pallas)

(N.B. Large specimens of $I$. viridis may have angled shoulders to the telson, but this brackish water species differs structurally from I. baltica by having a single aesthetasc at the tip of the antennule, instead of a pair, and coxal plates 2, 3 and 4 do not reach the posterior border of the segment as they do in $I$. baltica.)

(b) Telson apical border not tridentate, almost invariably rounded laterally.

(i) Antenna shorter: segment 3 of peduncle, viewed from below, not longer than its maximum width: flagellum usually $<\frac{1}{5}$ body length (Fig. II). Antennule stouter (Fig. I), the number of aesthetascs exceeding the length of the body in millimetres. t, adult appendix masculinus protrudes beyond 2nd pleopod (Fig. 7). Intertidal, amongst algae or barnacles.

(aa) Antenna very short: only segment 5 of peduncle longer than wide: flagellum markedly shorter than peduncle (Fig. 2). Telson broadly rounded; in adults with a small median point which is obtuse (Fig. 8). Colour mostly purplish with white patterning. Frequents exposed barnacle-covered rocks, sheltering in algal tufts, dead barnacles, etc. 
(bb) Antenna less short: peduncle with segments 4 and 5 longer than wide, and flagellum about as long as peduncle (Fig. 2). Telson narrower, with shallow concavity along its sides, its apical margin typically with a distinct median process which is acute (but rounded at the tip (Fig. 8)). Colour mostly red, brown or green. Large specimens frequent fucoids in the mid-tidal zone; smaller specimens amongst Cladophora etc.

I. granulosa Rathke

(ii) Antenna longer: segment 3 of peduncle viewed from below longer than maximum width, flagellum equal to or more than $\frac{1}{5}$ body length (Fig. 2). [If the flagellum is about equal to $\frac{1}{5}$ body length, but the sides of the telson are slightly concave, turn to $(i, b b)$ above.] Antennule more slender (Fig. I), the number of aesthetascs equal to or less than body length in millimetres. $\delta^{t}$, appendix masculinus does not project beyond the and pleopod in the marine species.

(aa) Body more slender, width $=\frac{1}{4}$ length, or less. Head narrow, only $\mathrm{I} \frac{1}{2}$ times as wide as its median length. Coxal plates 3 and 4 not reaching posterior margin of segment. Antennule tip with single aesthetasc, longer than the rest (Fig. I). Adult $\delta$ appendix masculinus extending to or just beyond tip of 2nd pleopod (Fig. 7). Colour mostly uniformly green or brown. Confined to brackish water, sometimes in pools above H.w.

I. viridis Slabber

(bb) Body more robust, width $>\frac{1}{4}$ length. Head wider, at least $\mathrm{I}_{4}^{3}$ times as wide as long. Coxal plates 3 and 4 reaching posterior border of segment. Antennule with paired aesthetascs at tip (Fig. I). $\hat{\sigma}$, adult appendix masculinus not reaching tip of and pleopod (Fig. 7). Marine, from L.w.S. downwards, amongst weed and sometimes under stones.

I. neglecta Sars

(N.B. The telson of this species is broader than in I. viridis and I. granulosa, but more pointed at the apex than in I. pelagica.)

\section{SPECIFIC DESCRIPTIONS}

Idotea pelagica (Fig. II)

Body short and stout; $3-3 \frac{1}{2}$ times as long as broad. Cephalon rather more than $\mathrm{I} \frac{1}{2}$ times as broad as long in the mid-dorsal line; anterior and posterior borders slightly concave. Antennule extending well beyond the second, but hardly beyond the third, segment of the antennal peduncle; first segment not greatly expanded in relation to the other segments, which are all robust. Aesthetascs in pairs, numbering up to 16 in males and up to 12 in females; aesthetascs greater in number than the body length in millimetres. Antenna very robust; flagellum by no means as long as peduncle and less than $\frac{1}{6}$ body length; most segments of flagellum broader than long, and with pads of fine hairs in adult males; segments numbering up to about 9 in both sexes, with terminal joint very stout and about $\frac{1}{4}$ the length of the subterminal segment. Coxal plates fairly broad, widening posteriorly and reaching posterior border of segments 4-7. Legs all very robust, the terminal claw being relatively larger than that 
of any other species; all legs after the first have pads of fine setae on their inner surfaces, in adult males. Abdomen with broadly rounded telson having a short median, obtuse tooth; not keeled. Appendix masculinus extending beyond the tip of the and pleopod for nearly $\frac{1}{2}$ its own length in small males $(4-5 \mathrm{~mm}$ ) and for $\frac{1}{4}$ its length in large males (IO-I I mm).

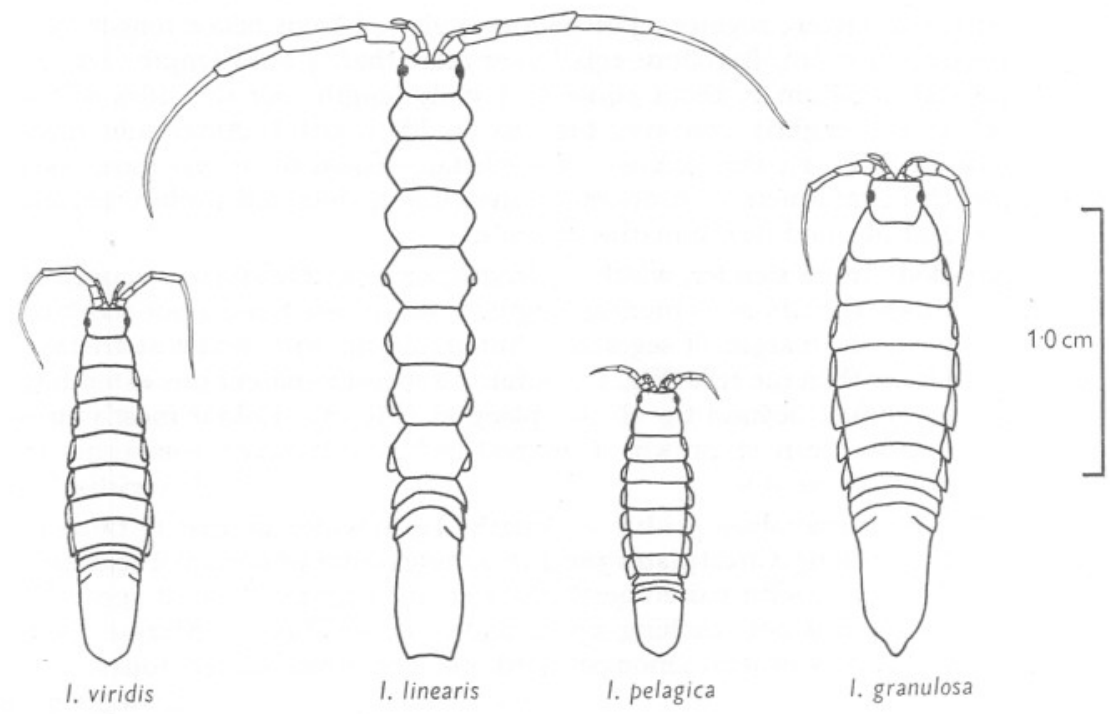

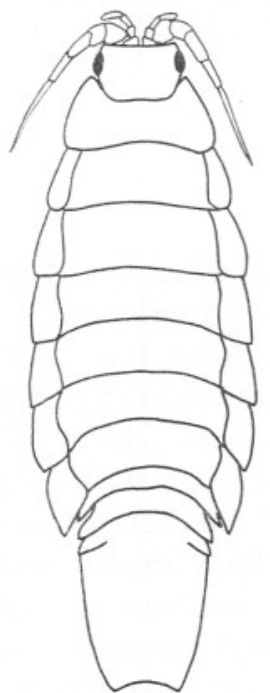

1. emarginata

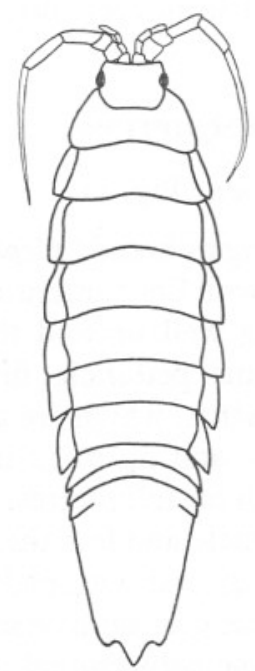

1. baitica

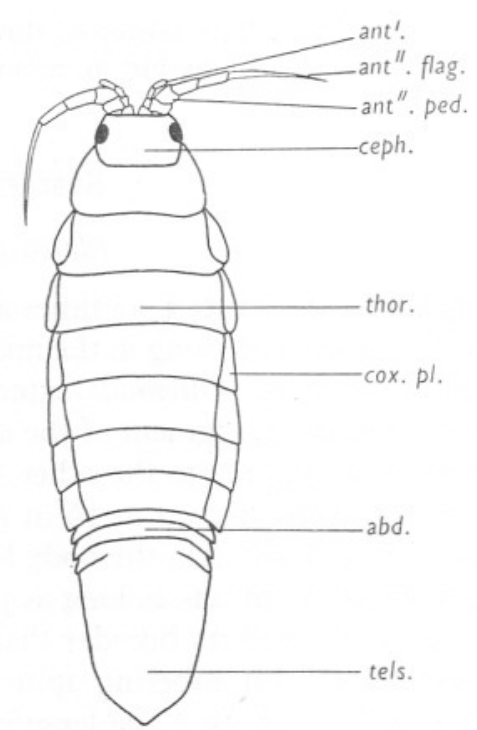

I. neglecta

Fig. II. Adult males of seven species of Idotea, seen from above. 
Length at release from brood pouch I-2 mm; males recognizable at about $4 \mathrm{~mm}$, ranging to II $\mathrm{mm}$; females 7-IO $\mathrm{mm}$.

Colour: mostly dark purple-brown, with white diamond-shaped patches or elongated stripes down the mid-dorsal line, and with white markings along the edges of the dorsal side; females often darker than males.

Habitat: typically on shores exposed to wave action, where weeds are stunted and barnacles abundant. The colouring merges well with the background of barnacles.

\section{Idotea granulosa (Fig. II)}

Body oval, narrowing rather sharply posteriorly; length often rather more than $3 \frac{1}{2}$ times the width. Cephalon about $\mathrm{I} \frac{1}{2}$ times as broad as long; anterior border almost straight, posterior border somewhat concave. Antennule extending beyond the second, but not beyond the third, segment of the antennal peduncle; first segment somewhat expanded, the second rather less so, and the others robust. Aesthetascs arranged in pairs, numbering up to 22 or more in males, and up to 16 or so in females; aesthetascs greater in number than the body length in millimetres. Antenna robust, flagellum not reaching length of peduncle (except possibly in largest males), and usually less than $\frac{1}{5}$ body length; segments of the flagellum numbering up to 16 in males, and $I_{3}$ in females; largest males have tufts of setae on the flagellum; terminal segment pointed, and about $\frac{1}{3}$ the length of the subterminal one. Coxal plates fairly narrow, broadening posteriorly, and not extending to the posterior border until segment 4 and posterior ones. Legs robust; the second leg of adult males having pads of fine setae on the inner surfaces of the 4 most distal joints. Abdomen narrowing sharply at first, with rather concave lateral sides; telson with long, acute, median spine and very obtusely rounded lateral shoulders; not keeled. Appendix masculinus in smaller males projecting by about $\frac{2}{5}$ its own length, but only for about $\frac{1}{10}$ its own length in larger specimens (15-20 mm).

Length at release from the brood pouch $2 \mathrm{~mm}$; some males recognizable at $5 \mathrm{~mm}$, ranging to $20 \mathrm{~mm}$ or a little more; adult females $6-13 \mathrm{~mm}$.

Colour: mostly uniformly brown, red or green, depending on the nature of the weed inhabited; occasionally with longitudinal white markings.

Habitat: predominantly a shore form, particularly abundant on Ascophyllum, and fucoids; smaller individuals prefer small weeds such as Cladophora and Polysiphonia. Occasionally on drift weed.

\section{Idotea viridis (Fig. II)}

Body slender; length 4-5 times the width, though sometimes less, particularly in adult females. Cephalon about $\mathrm{I} \frac{1}{2}$ times as broad as long; hardly concave, either anteriorly or posteriorly. Antennule extending well beyond the third peduncular joint of the antenna; first joint expanded, others slender. 
Aesthetascs usually arranged in pairs except for a single one, slightly larger than the rest, situated at the extreme tip of the antennule (any other single ones are added to at the next moult); aesthetascs number up to II in males, and up to 9 in females. Antenna long and slender; flagellum longer than the peduncle except in very small forms, and about $\frac{1}{4}$ the body length; segments of the flagellum numbering up to $\mathrm{I} 8$ in males, and up to $\mathrm{I} 3$ in females; terminal style roughly cylindrical, about $\frac{1}{2}$ the length of the subterminal segment. Coxal plates narrow, increasing in size posteriorly, and only those of segments 5, 6 and 7 reaching the posterior border of the segment. Legs long and very slender, second limb of adult males bearing pads of fine hairs. Abdomen with sides subparallel, slightly keeled posteriorly in the mid-dorsal line; telson with a single, median tooth, hardly acute, and with obtuse lateral corners. Appendix masculinus of most males projecting for about $\frac{1}{10}$ of its own length beyond the second pleopod, though hardly projecting at all in the largest males.

Length when first released from the brood pouch I-2 mm; males recognizable often from about $5 \mathrm{~mm}$, ranging to $15 \mathrm{~mm}$; adult females range from 6 to $10 \mathrm{~mm}$.

Colour: mostly uniformly green or brown, sometimes with white markings; females often darker than males, as with all species.

Habitat: prefers brackish water; often in brackish pools above H.W.N., which are not continuously reached by the sea. It is also recorded from the tidal region in estuarine conditions.

\section{Idotea linearis (Fig. II)}

Body very slender; length 4-7 times the width, but mostly between 5-6 times. Cephalon nearly twice as broad as long; deeply concave anteriorly, and slightly so posteriorly. Antennule extending just beyond the second peduncular joint of the antenna; first joint very much expanded and rounded, others slender. Aesthetascs long and slender, arranged in pairs except for a terminal one separate from the rest; numbering up to $\mathrm{I} 9$ or more in adult males and I7 or more in adult females. Antenna very long and slender, peduncle rather longer than the flagellum; flagellum about $\frac{1}{3}$ body length, having up to about 20 segments in males and rather less in females; terminal style pointed, less than $\frac{1}{2}$ the length of the subterminal segment. Coxal plates very small, never extending to the posterior border of any segment. Legs long and slender, becoming somewhat palmate distally: in addition to the usual armature of spines, the second and succeeding legs of adult males have pads of fine setae on their inner borders. Abdomen with sides slightly incurved: telson with concave posterior border, and with a small median spine in young specimens. Appendix masculinus extending well beyond the tip of the second pleopod, by about $\frac{1}{3}$ its own length, or rather less, in adult males. 
Length at release from the brood pouch between 2 and $3 \mathrm{~mm}$; males often recognizable from about $15 \mathrm{~mm}$, ranging to over $20 \mathrm{~mm}$ in length; females rather less in size.

Colour: green or brown, with darker or lighter longitudinal stripes; adult female often darker than male, frequently with paler markings around the edges.

Habitat: usually sublittoral, associated with drift weed or bottom living algae, though occasionally found intertidally.

\section{Idotea baltica (Fig. II)}

Body oblong oval; length usually more than 3 times the width. Cephalon width rather more than $\mathrm{I} \frac{1}{2}$ times length; somewhat concave anteriorly and posteriorly. Antennule extending to or just beyond the distal end of the 3 rd segment of the antennal peduncle; ist and 2nd joints expanded, others elongated and fairly robust. Aesthetascs in pairs, numbering up to about 20 in males and about 16 in females. Antenna slender, with flagellum longer than peduncle and about $\frac{1}{4}$ the body length; flagellum segments numbering up to 20 in males and 15 or so in females; terminal style pointed, and about $\frac{1}{3}$ the length of the subterminal segment. Coxal plates large in adults, extending from anterior to posterior borders of all segments from the 2nd or 3 rd backwards, becoming wider posteriorly. Legs fairly robust; 2 nd leg of adult males having pads of fine setae. Abdomen dorsally keeled, with more or less straight sides, tapering to a tridentate telson; median process long and acute, lateral processes smaller (obtuse and less pronounced in young specimens). Appendix masculinus reaching just about the end of the 2nd pleopod in smaller males, but failing to do so by about $\frac{1}{10}$ of its own length in larger males.

Length about $2 \mathrm{~mm}$ in newly released juveniles; males first recognizable at about $10 \mathrm{~mm}$, ranging to $30 \mathrm{~mm}$; adult females $10-18 \mathrm{~mm}$.

Colour: sometimes uniformly green or brown, but often with white marbling in the form of spots, or pale longitudinal lines, particularly along the edges; female often darker than male.

Habitat: generally sublittoral, but not infrequently found on the shore, e.g. on Halidrys at L.w.M.; often on drift weed.

\section{Idotea neglecta (Fig. II)}

Body oblong oval; length a little more than 3 times the width. Cephalon rather more than $\mathrm{I} \frac{1}{2}$ times as broad as long: concave anteriorly and posteriorly. Antennule extending to (or nearly to) the distal end of the 3rd joint of the antennal peduncle; Ist and 2nd joints expanded, others elongated and fairly robust. Aesthetascs in pairs, numbering up to $\mathrm{I}_{2}-\mathrm{I}_{4}$ in males, and IO-I2 in females. Antenna fairly slender, flagellum longer than peduncle and $\frac{1}{5}-\frac{1}{4}$ the 
body length; flagellum segments numbering up to 20 in males and up to about I4 in females; terminal style pointed and averaging $\frac{1}{3}$ the length of the subterminal segment. Coxal plates wide, extending the whole length of the segment from the 2 nd or 3 rd to the last. Legs robust, the 2 nd legs of adult males having pads of fine setae. Abdomen with sides fairly straight and converging posteriorly, with hind border of telson characterized by a median obtuse tooth, and obtusely rounded lateral shoulders; keeled. Appendix masculinus fails to reach the tip of the second pleopod by up to $\frac{1}{3}$ of its own length.

Length on release from the brood pouch about $2 \mathrm{~mm}$; males recognizable from about $8 \mathrm{~mm}$, ranging to nearly $30 \mathrm{~mm}$; adult females range from Io to I6 $\mathrm{mm}$.

Colour: often uniformly brownish, sometimes with white longitudinal lateral markings, and occasionally with white marbling over the whole dorsal surface; adult females mostly darker than males.

Habitat: generally sublittoral, often on accumulations of organic matter rather than on attached weed; occasionally on surface drift weed.

\section{Idotea emarginata (Fig. II)}

Body oblong oval; length hardly more than 3 times the width. Cephalon about $\mathrm{I} \frac{3}{4}$ times as broad as long; both anterior and posterior borders concave. Antennule extending beyond the 3 rd joint of the antennal peduncle; first and second joints expanded, others fairly robust. Aesthetascs in pairs; numbering up to $\mathrm{I} 6$ in males, and up to about I4 in females. Antenna somewhat robust, flagellum longer than peduncle and about $\frac{1}{6}-\frac{1}{5}$ the length of the body; flagellum segments numbering up to about I8 in males and 14 in females; terminal style pointed, and about $\frac{1}{3}-\frac{1}{2}$ the length of the subterminal segment. Coxal plates broad, extending over the whole length of the segment in segments 2 or 3 and posterior ones; becoming wider posteriorly. Legs robust; second leg of adult males having setose pads. Abdomen with sides curving slightly outwards, and with an emarginate telson, the lateral shoulders forming two obtuse points which are recognizable from a size of about $5 \mathrm{~mm}$ onwards; telson at first bluntly rounded, then cut straight across, then showing the emarginate character as growth proceeds. Appendix masculinus almost reaching the tip of the second pleopod in small males, though it fails to do so by up to $\frac{1}{4}$ of its own length in adult males.

Length when first released from the brood pouch about $2 \mathrm{~mm}$; males first recognizable from 7-9 $\mathrm{mm}$, depending on the season of release, and ranging to about $30 \mathrm{~mm}$; adult females from 9 to $\mathrm{I} 8 \mathrm{~mm}$.

Colour: males, particularly, often uniformly brown in colour, though sometimes with white markings; females generally darker in colour, often with 
longitudinal lateral white bands, or alternating white and darker transverse bands.

Habitat: generally sublittoral on accumulations of algae, though occasionally on drift weed.

\section{SUMMARY}

Detailed descriptions of the external morphology, from the functional and developmental aspects, are given for seven species of Idotea. The taxonomic value of various structures is discussed in relation to previous work on the genus, and a key to the identification of Idotea is given. Specific descriptions are revised.

\section{REFERENCES}

Bate, C. S. \& Westwood, J. O., I868. A History of the British Sessile-Eyed Crustacea, Vol. 2, $536 \mathrm{pp}$. London: van Voorst.

Calman, W. T., I909. Crustacea. A Treatise on Zoology (ed. Ray Lankester), Pt. 7. London.

Collinge, W. E., I9I7. A revision of the British Idoteidae. Trans. roy. Soc. Edinb., Vol. 5I, pp. 72I-60.

- I9I8. Oral appendages of marine Isopoda. F. Linn. Soc., Vol. 34, pp. 65-93.

Dollfus, A., I894-5. Les Idoteidae des côtes de France. Feuill. jeun. Nat., T. 25, pp. I-5, I7-I8, 38-40, 53-5.

Gilmour, J. S. L., 1952. The development of taxonomy since 185I. Advanc. Sci., Vol. 9, No. 33, pp. 70-4.

Hansen, H. J., 1925. Studies on the Arthropoda, Vol. 2. Copenhagen.

HoLthuIS, L. B., I949. The Isopoda and Tanaidacea of the Netherlands, including the description of a new species of Limnoria. Zoöl. Meded., Deel 30, pp. I63-90.

Howes, N. H., 1939. Observations on the biology and post-embryonic development of Idotea viridis from New England Creek, south-east Essex. F. Mar. biol. Ass. U.K., Vol. 23, pp. 279-3IO.

Huxley, J. S., 1932. Problems of Relative Growth. London.

KJENNERUD, J., I950. Ecological observations on Idothea neglecta G. O. Sars. Univ. Bergen Arb. naturv. R., Nr. 7, pp. I-47.

MOoRE, H. B. (ed.), I937. Marine Fauna of the Isle of Man. Liverpool University Press.

NAYLOR, E., I955a. The ecological distribution of British species of Idotea. F. Anim. Ecol. (in the Press).

- I955b. The diet and feeding mechanism of Idotea. F. Mar. biol. Ass. U.K., Vol. 34, pp. 347-55.

- I955c. The life-history of Idotea emarginata Fabricius. F. Anim. Ecol. (in the Press).

Nierstrasz, H. F. \& SteckHoven, J. H., jun., 1930. Isopoda genuina. Tierwelt N.- $u$. Ostsee, Tl. ro, e 2, (Lf. 18), pp. 57-133. Leipzig.

SARS, G. O., I899. Isopoda. An Account of the Crustacea of Norway, Vol. 2, 270 pp. Bergen.

TAtTersall, W. M., I906. The marine fauna of the coast of Ireland. Pt. 5. Isopoda. Rep. Sea Inl. Fish. Ire., Sci. Invest., year 1904, No. 2, 90 pp.

- I9Ir. Die nordischen Isopoden. Nord. Plank., Abt. 6, pp. I8I-313. 